\title{
THEORETICAL AND METHODICAL BASES OF CONSTRUCTING THE ACCOUNTING SYSTEM AND COST ANALYSIS FOR THE PRODUCTION COST OF THE FOOD INDUSTRY OF KAZAKHSTAN
}

\author{
Saule Spatayeva ${ }^{1}$, Diana Ismailova ${ }^{2}$, Almagul Nurgalieva ${ }^{3}$
}

\begin{abstract}
Theoretical and practical significance of the work consists of the fact that the proposed development will result in scientific achievements in the field of accounting and cost analysis of finished products and their application in practice. The theoretical value boils down to accounting for the cost of production using the principles of International Financial Reporting Standards (IFRS), structural-logical model of factor analysis input intensities of production in the food industry, and improving analytical accounting cost of the finished product by the cost centers and responsibility centers. Research results and proposed guidelines can be used in the food industry as a methodical support to managers and accountants of enterprises. The reliability of the results of the research confirmed their practical use in the food industry.

The proposed method of cost accounting for production and calculation of the production cost are used in enterprises in Astana and Akmola regions.
\end{abstract}

JEL Classification Numbers: L3, L8, M4, DOI: http://dx.doi.org/10.12955/cbup.v3.598

UDC Classification: 330

Keywords: costs, expenses, calculation, domestic, production, methods, management

\section{Introduction}

The food industry in Kazakhstan is a sector of the economy that aims to ensure a steady and essential supply of quality food products. On the one hand, this industry represents the leading sector of the economy and on the other, the final link, and base of the food industry. Growth in volume and improvements in the quality of food, directly affect costs, profits, and profitability of the industry.

Today, industrial enterprises focus on significantly increasing food production, which implies a constant search for ways to reduce costs and improve quality. There are a host of scientific and methodological developments, and practical recommendations, but these generally fail to consider the complexity of accounting and analytical procedures. Therefore, this study of calculating final costs of food production with comprehensiveness and continuity in accounting and analytical systems is relevant and timely.

The theoretical and methodological bases of the article originate from works of Russian and foreign scientists in line with integrating, analyzing and calculating production costs, as well as laws and regulations, and information in scientific and methodical literature, periodicals, and materials of scientific conferences and seminars.

Various scientific methods (dialectics, analysis, synthesis, analogy), special methods and accounting procedures (accounts, documentation, double entry, evaluation, reporting), and other analysis (horizontal, vertical, trend, factor) were used for the results presented in the article.

Theoretical and practical significance of the work pertains to scientific achievements in the field of accounting, and cost analysis of finished products and their application in practice. The theoretical value of this study is in providing methods to account for production cost, based on the principles of IFRS; a structurally logical model of factor analysis for intensities of production in the food industry; and improved analytical accounting estimates of the finished product by cost centers and other responsible areas. Such research results and proposed guidelines have value in the food industry as a methodical

\footnotetext{
${ }^{1}$ Saule Spatayeva JSC, Kazakh Agrotechnical University named after S. Seifullin, Master of Economic Sciences, Ph.D doctoral in Varna Free University (Bulgaria), idt12@mail.ru

${ }^{2}$ Diana Ismailova, LTD, Academy of Imageology, Rector, Professor, Candidate of Philological Sciences, imageology@mail.ru

${ }^{3}$ Almagul Nurgalieva, LTD, Academy of Imageology, Vice-President, Candidate of Economic Sciences, Docent, nurgalieva_as@mail.ru
} 
support for enterprise managers and accountants. The reliability of research results confirms their practical use in the food industry.

The proposed method of cost accounting and calculation of the production cost is used in enterprises of Astana and Akmola region.

\section{Terminological analysis and economic characteristics of the production cost in the food industry}

The food industry is a part of a much wider commercial enterprise, bringing together various sectors. It involves food-processing plants, that produce edible goods for the consumer, and usually involves processing raw agricultural materials with special techniques, machinery, devices, and trained staff.

The food industry closely connects with all sectors of the national economy, including many that have a direct impact on people's lives (Figure 1).

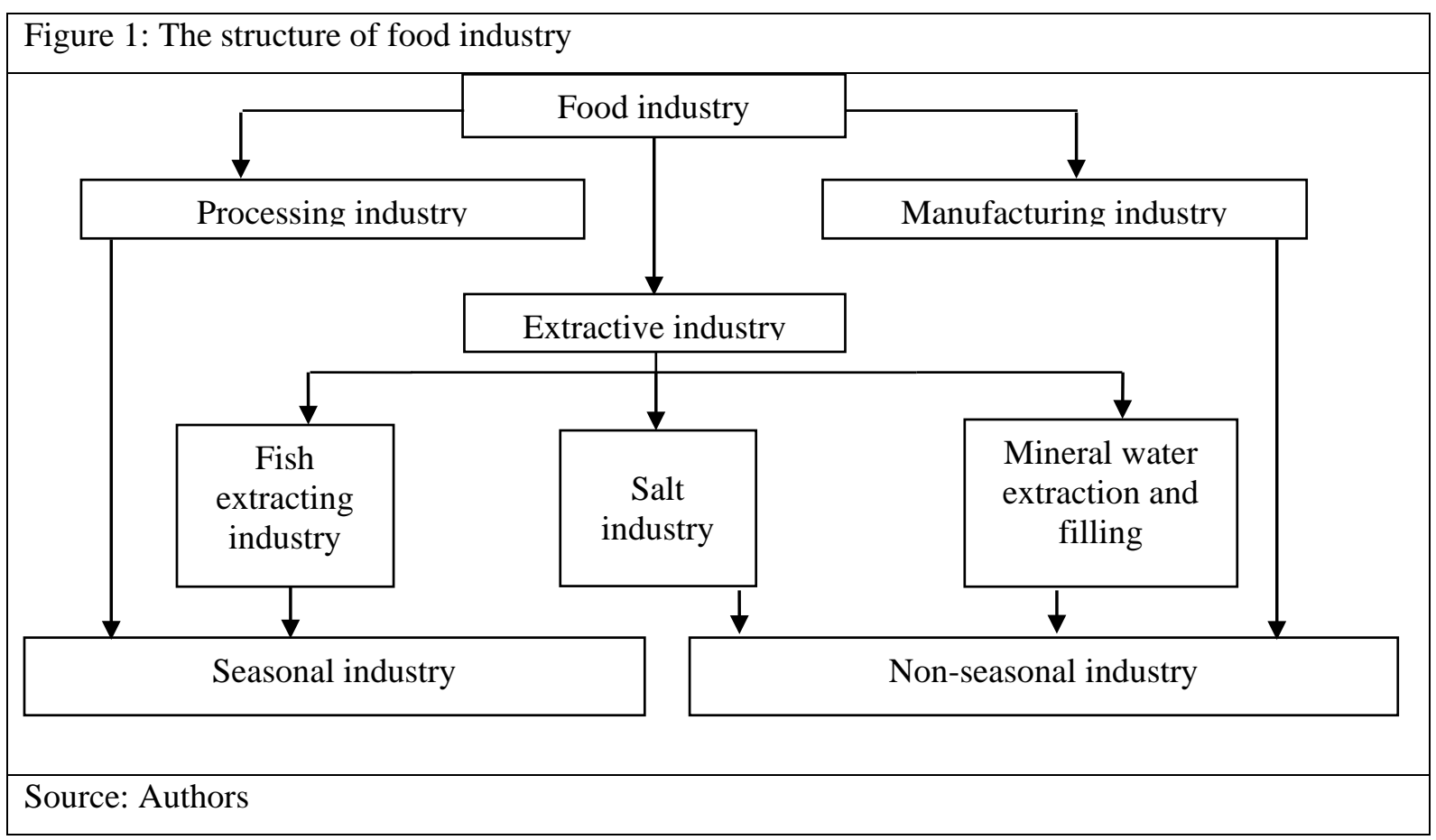

However, the food and agricultural industries are the most interdependent, and an agro industrial complex exists because of the close relationship between these major branches. Therefore, the food industry overall is legitimately regarded as a part of the agro-industrial complex and processing industry.

Food industry branches oversee production and labor (branch A) and consumer goods (branch B). Branch A accounts for about one third, while branch B accounts for the remainder of the commodity output. Ultimately, the food industry is about consumer goods that are food products (branch B).

The food processing industry of Kazakhstan is a strategic sector of the economy, intended to ensure a steady and essential supply of quality food. The food processing industry (food, meat, dairy, fish, flour, cereals, and feed mill) has more than 28000 associations, corporations, enterprises, and shops (the number has increased 3.5 times in recent years). These employ about 1.5 million people in more than half the food trade. These industries generate almost all the necessary food for the population, including special products for children. The constant growth in needs and demand for food products, reflected in the volume of product sales in the food industry compared to other industrial products, indicates the primacy of the food industry

The economic preconditions for the development of food industry are shown in Figure 2. 


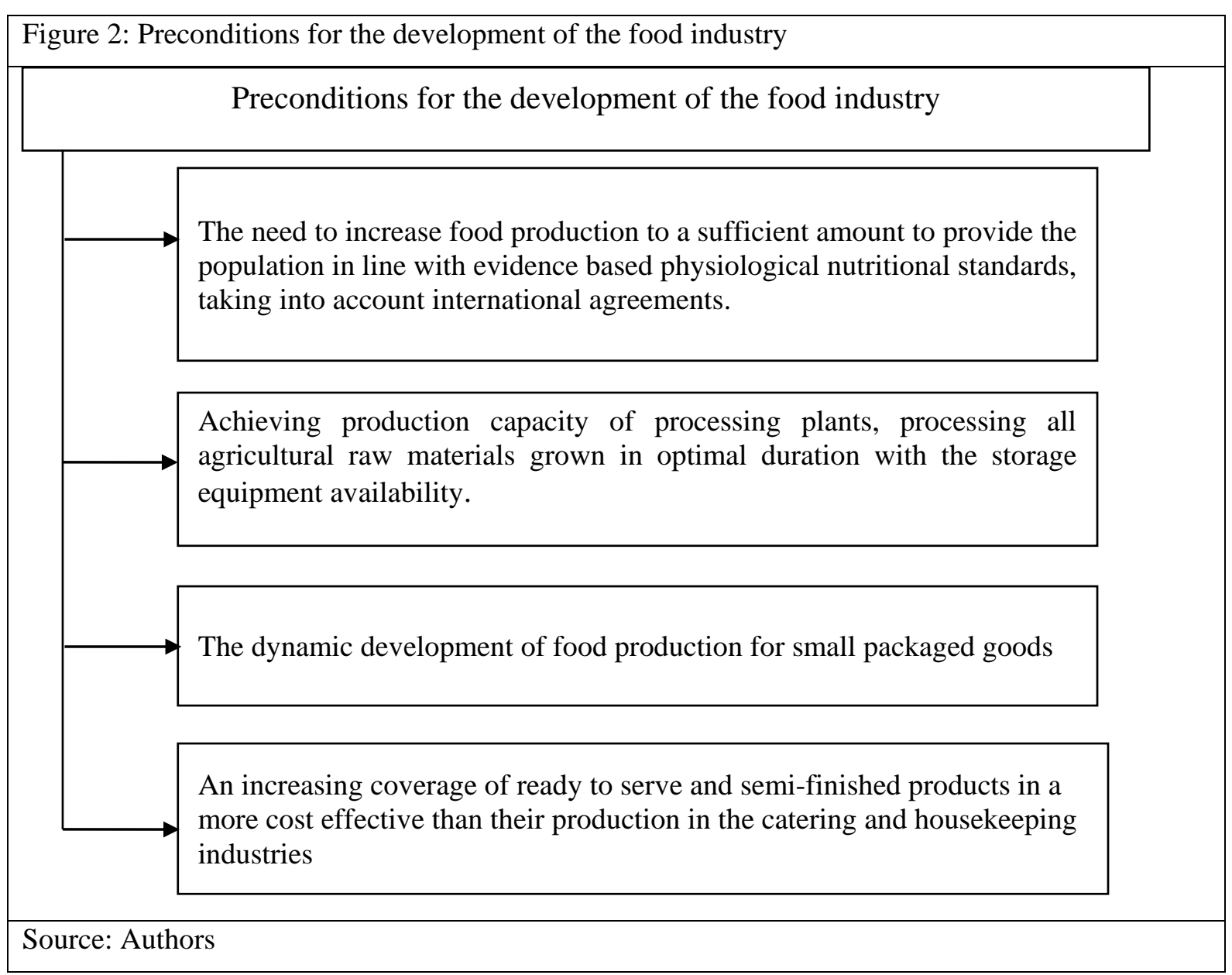

As the food processing industry is an integral part of the whole economy, along with agriculture, it represents a leading economic sector. Additionally, it is the final link, and the base of the food industry. Therefore, the construction of an integrated system of accounting and cost analysis to calculate the cost of the finished product is relevant and timely.

The price of products on the market is a consequence of the interaction of supply and demand. That is, it aligns automatically rather than by the wishes of the manufacturer or buyer, based on free competition laws of market pricing. Current expenses may increase or decrease depending on human consumption and material resources, e.g. equipment level, production, and similar factors. These give the manufacturer many levers to reduce costs, with skillful leadership. The important terms in economics include costs, expenses, production costs, and calculation, not only in accounting, but also in analysis and identifying falling reserves. The level of expenses largely determines the profit margin and profitability of an enterprise, and the efficiency of its business. Reduction and optimization of costs are among the main avenues of improving economic performance of each enterprise, and determining its competitiveness, reliability, and financial stability.

In foreign literature, costs refer to production costs and distribution costs and there are several types, including material, labor, repairs and restoration of fixed assets, and others (for communication, social and cultural needs).

According to Rudenko (2005) costs are amounts spent on purchasing available resources. They are recorded as assets in the balance sheet of the company, and are capable of earning income in the future.

Costs that are expenses incurred for economic gain (decrease of assets or increase in liabilities) usually relate to the assets providing incomes. Costs are also the sacrifices made for goods or services. In this sense, costs are an asset. 
The term "expenses" characterizes the production costs of a certain period.

The costs are fees expressed in monetary form for something or resources "decimated" in the production process in order to obtain certain products (goods and services).

Among foreign authors, Anthony \& Rice (2001) noted that cost (expenses) is the monetary expression of the value of resources used for specific purposes. These authors emphasize the definition includes three major provisions. First, the basic costs are determined by using resources, which are elements of costs in the production of goods and services related to the amount of consumed materials, the number of work hours, and the amount of other expended resources. The cost (prime cost) reflects the quantity of resources used. The second is the value of used resources in monetary terms. Money provides the unity of measure to encapsulate the various resources. The third is the definition of the cost (prime cost) relating to specific goals or objectives. These may include manufacturing, operations, or any other object or activity that determines the amount of resources used in monetary terms.

Horngren and Foster (1995) support this position of prime cost as the cost of the resources controlled by the corporation, which are actually incurred costs.

Many authors assign a specific function to the prime cost, in terms of the cost parameters, to ensure the continuity of the production process.

The nature of the cost reflecting the social costs of production and isolated parts of the product cost. This indicates the cost of production and wages incurred, and accounts for the ongoing production.

Production cost is not only an important economic category, but also a quality indicator, as it characterizes the level of utilization of all resources (variable and constant capital), held by the company.

As an economic category, the production cost performs the following important functions:

- accounting and control of all production and sale costs;

- the basis for wholesale prices for the company's products, and the definition of income and profitability;

- the real investment in a feasibility study of the reconstruction, modernization, and expansion of existing businesses;

- determines the optimal components of the enterprise, a feasibility study, and the adoption of any administrative decisions.

To consider cost as an objective economic indicator, it is necessary to understand the general principles of its origins. This would determine the composition and features of the costs incurred in production. Several researchers (Bezrukih, Ivashkevich, \& Kondrakov, 1996; Komissarova, 2002) consider the basic principle as the direct relationship between cost and production. Another considers the nature of the transfer value of production in the value of the product, according to which the cost of the reproduction of labor is distinguished from objects of labor directly included in the production cost.

Nikolayeva (2000) formulated the principles of costs clearly, when she considered the production costs as an objective indicator that should not depend on the content of certain regulations, but on comprehensive economic principles, as follows:

- the connection with ongoing business organization;

- the separation of current and capital expenditures;

- the assumption of time definiteness of economic activity facts the accrual principle; and

- the assumption of property isolation of the organization. 
Thus, the follow provides a summation of the position of domestic scientists and foreign authors on the economic essence of "cost."

Costs of production are a set of calculated costs, representing a monetary value consumed in the process of resources production. In accordance with the accounting principles and financial reporting standards, the production cost becomes cost of sales from a decrease in the financial outcome.

The following provisions determine the value of production costs (works, services).

First, the production cost serves as the main indicator of production efficiency. It indicates the more effective use of economic resources of people, scientific discoveries in the manufacturing process, lower costs and higher profits, and hence higher resistance to competition.

Second, the data relating to production costs show the results of the independent farm activity in the market for the enterprise.

Third, the production cost is a factor determining prices. The lowest price limit without risk of large losses corresponds to the actual production cost.

Fourth, the cost is the main indicator in determining the productivity.

Fifth, the calculation of the production cost is necessary for estimating the efficiency of the introduction of new techniques, technologies, to inform decisions about the production of new products and the discontinuation of the legacy.

In summarizing the analysis of viewpoints on the concept under the study there are two basic approaches to the qualification of the categories of "costs", "expenses", "charges", and "costs of production " in order to create an integrated accounting and analysis system:

1) these categories have the same meaning and there is no need to allocate the difference between them; hypothetically it is considered that the "charges" are identical to "cost", and "expenses" are identical to "costs of production” (Horngren \& Foster, 1995; Nikolaeva, 2000; Brusentsova, 2002; Nikolaeva \& Shishkova, 2009; Kukukina, 2011);

2) “charges”, “costs”, “expenses”, and "costs of production” are varying notions (Ivashkevich, 2003; Kondrakov \& Ivanova, 2003; Kondrakov, 2008; Kotliarov, 2002; Sokolov, 2004; Popova, Golovina, \& Maslova, 2006; Popova, 2001; 2007; Khamidullina, 2004).

The second point of view appears more accurate. We consider the use of the term "charges" as unnecessary in accounting, and the term "costs" as the offer of resources used in monetary terms for the purposes of economic activities. We agree with the statutory definition of the term "expenses", which refers to a decrease in economic benefits from the disposal of assets or incurrence of liabilities, leading to a reduction in the capital of the organization (Strategic Business Unit, SBU, "Expenses of the organization"). The expenses of organization can be attributed to either assets or expenses of the organization.

The division of costs to sales ratio, period expenses, and expenses of the organization associated with the production and sale of goods (works, services) is important to evaluate the results of the economic activities of the organization, and its profitability. Schematically, the relationship between these terms in accounting is reflected in Figure 3.

Tax accounting uses the terms "expenses" and "costs." The Tax Code of the Republic of Kazakhstan (the Tax Code of the RoK, 2013) deems "costs" as that which is reasonably incurred and documented expenses of the taxpayer.

Moreover, this tax code recognizes costs as any outlay incurred while carrying out income generating activities. The term "expenses" defines costs, though not all costs are expenses in accounting and tax laws. 


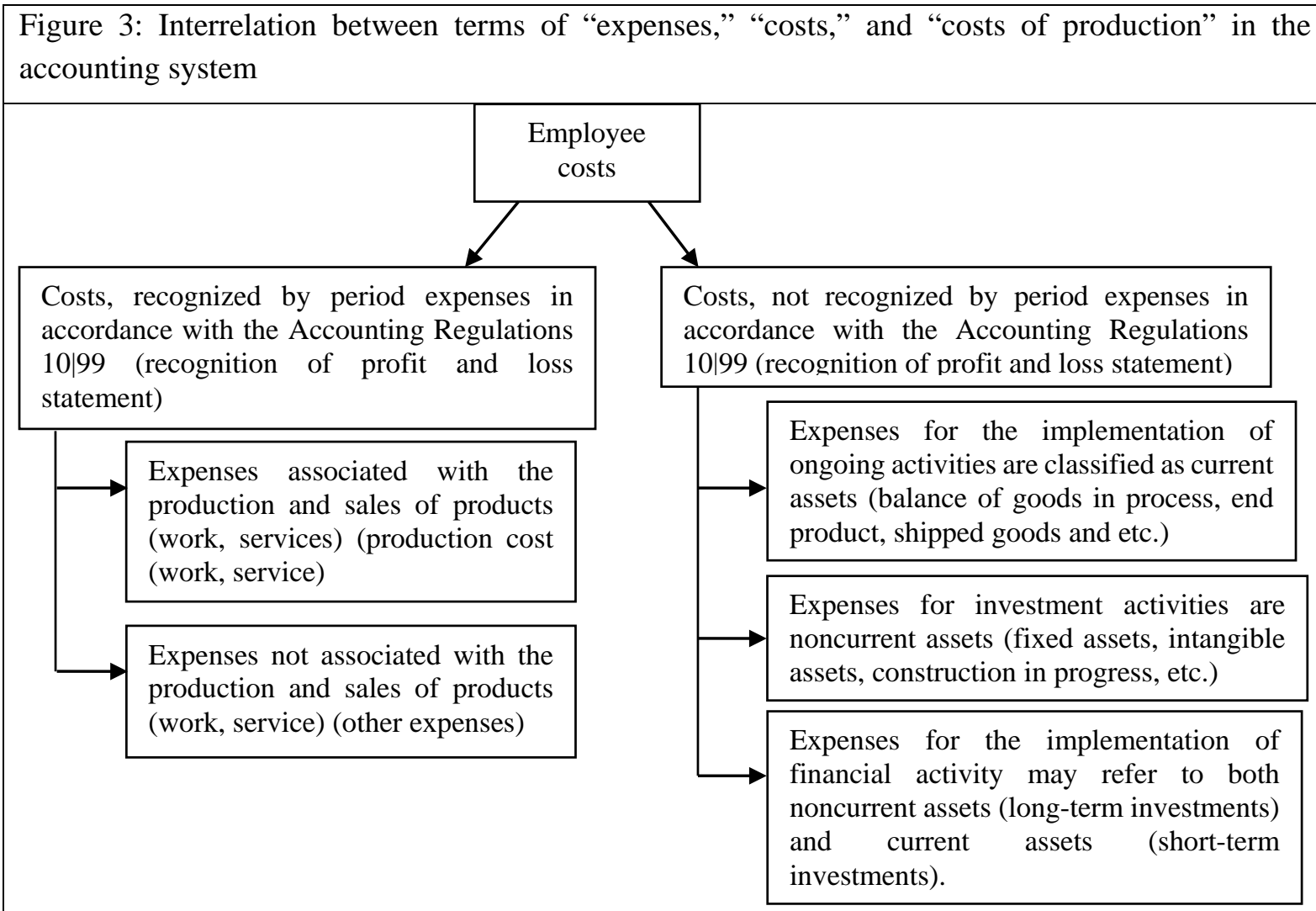

Source: Authors

The Tax Code of the RoK (2013) contains a detailed list of expenses and the conditions of their acceptance for tax purposes, and does not include categories of "charges" or "cost of production."

The term "expenses" is identical to the notion of "costs" and, in cases stipulated by the Tax Code of the RoK (2013), to the notion of "losses". These are losses, which in some cases are included in the costs, such as negative differences from the sale of fixed assets, and losses on securities transactions. The Tax Code of RoK (2013) gives its own interpretation of economic terms for tax purposes.

Tax expenditures represent only a part of expenses in accounting, i.e. not all costs in the accounting records equate to expenses for tax purposes. However, the expenses in accounting represent a fraction of the entire expenses of the organization, i.e. accounting does not deal with all expenses incurred by the enterprise. Inequalities are due to the existing requirements of accounting and tax legislation.

In international practice, there are no requirements to qualify expenses and no corresponding analogue standard SBU, as it is difficult to regulate the accounting of expenses because of their diversity and difference between types. The "Basis of preparation of the financial statements" International Financial Reporting Standard (IFRS), provides a fundamental definition of expenses, sufficiently explained to indicate the particular category.

The Western accounting system, involving financial and management subsets, does not require the user to qualify or classify, in detail, all possible costs of the organization.

The classification of "charges”, “costs”, "expenses”, and "production cost” in economics, accounting, tax, and international accounting are shown in Table 1.

In our opinion, there is every reason to consider cost as the main indicator of an enterprise's economic activity. The analysis of additive costs, which are the costs in producing goods (works, services), indicates that the expenses included in the production cost are not the same in either composition or the manufacturing value of the goods. 
Some costs directly relate to the production of goods, for instance, the cost of raw materials, wages, and salaries. Others relate to the management and maintenance of production, for example the expenses to ensure the production proceeds with the necessary resources for maintaining fixed assets in working order. Then there are those that are unrelated to production process, but are regarded as costs due to legislation.

Furthermore, since some costs directly relate to producing goods, and others indirectly, there is the need to classify costs in order to identify the different types of expenses and the extent of their influence on production and profitability.

International practice shows that in economically developed countries, different versions of cost classification exist according to the target system, which directs the cost accounting.

In tax accounting, the economic factors do not determine the grouping of expenses, but rather the fiscal targets. A Kazakhstan organization is required to group expenses according to procedures of the Tax Code of the RoK (2013), which thwarts organizations from specifying their own.

\begin{tabular}{|c|c|c|}
\hline Types of classification & Classification of expenses & Regulatory acts \\
\hline $\begin{array}{l}\text { In terms of nature } \\
\text { and activity } \\
\text { peculiarities }\end{array}$ & $\begin{array}{l}\text { - } \quad \text { expenses, related with production and sales; } \\
\text { - } \quad \text { non-sale expenses }\end{array}$ & article 252 TC RF \\
\hline $\begin{array}{l}\text { Classification of } \\
\text { expenses, related } \\
\text { with production and } \\
\text { sales }\end{array}$ & 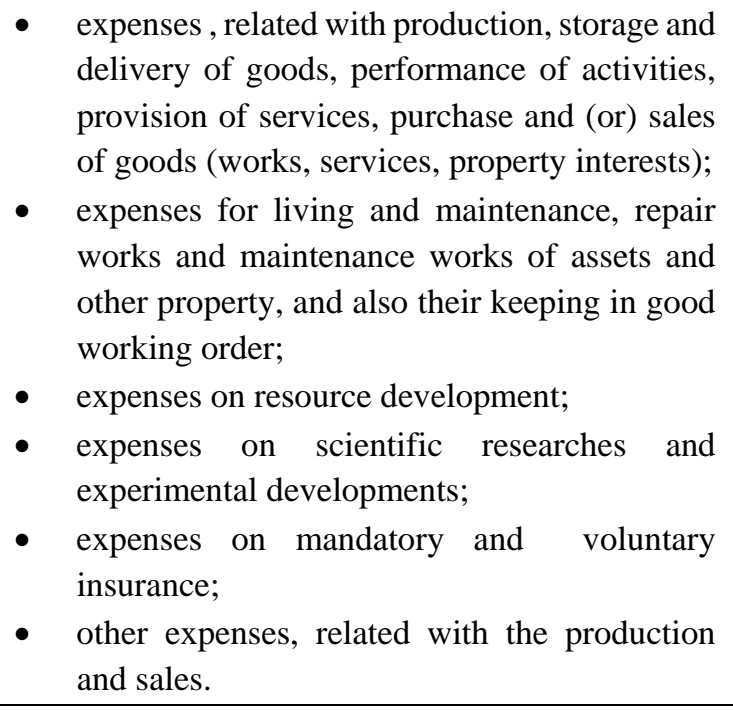 & article 253 TC RF \\
\hline $\begin{array}{l}\text { In terms of } \\
\text { elements }\end{array}$ & $\begin{array}{ll}\text { - } & \text { material expenses; } \\
\text { - } & \text { labor payment expenses; } \\
\text { - } & \text { amount of depreciation charges; } \\
\text { - } & \text { other expenses. }\end{array}$ & article 253 TC RF \\
\hline $\begin{array}{l}\text { By means of including } \\
\text { expenses for the } \\
\text { production and sales } \\
\text { into taxation basis }\end{array}$ & $\begin{array}{ll}\text { - } & \text { direct expenses; } \\
\text { - } \quad \text { indirect expenses. }\end{array}$ & $\begin{array}{l}\text { subparagraph } 1,4 \\
\text { paragraph } 4 \text {, article } 254 \text {, } \\
\text { article } 255 \text {, subparagraph } \\
\text { 1, paragraph } 1 \text { article 264, } \\
\text { article } 256259 \text { TC RF }\end{array}$ \\
\hline $\begin{array}{l}\text { By means of } \\
\text { accordance of } \\
\text { expenses with a view } \\
\text { to taxation basis }\end{array}$ & $\begin{array}{l}\text { expenses for the production and sales of own } \\
\text { goods (works, services), and also expenses, } \\
\text { incidental to property and property interests } \\
\text { selling; }\end{array}$ & article 315 TC RF \\
\hline
\end{tabular}




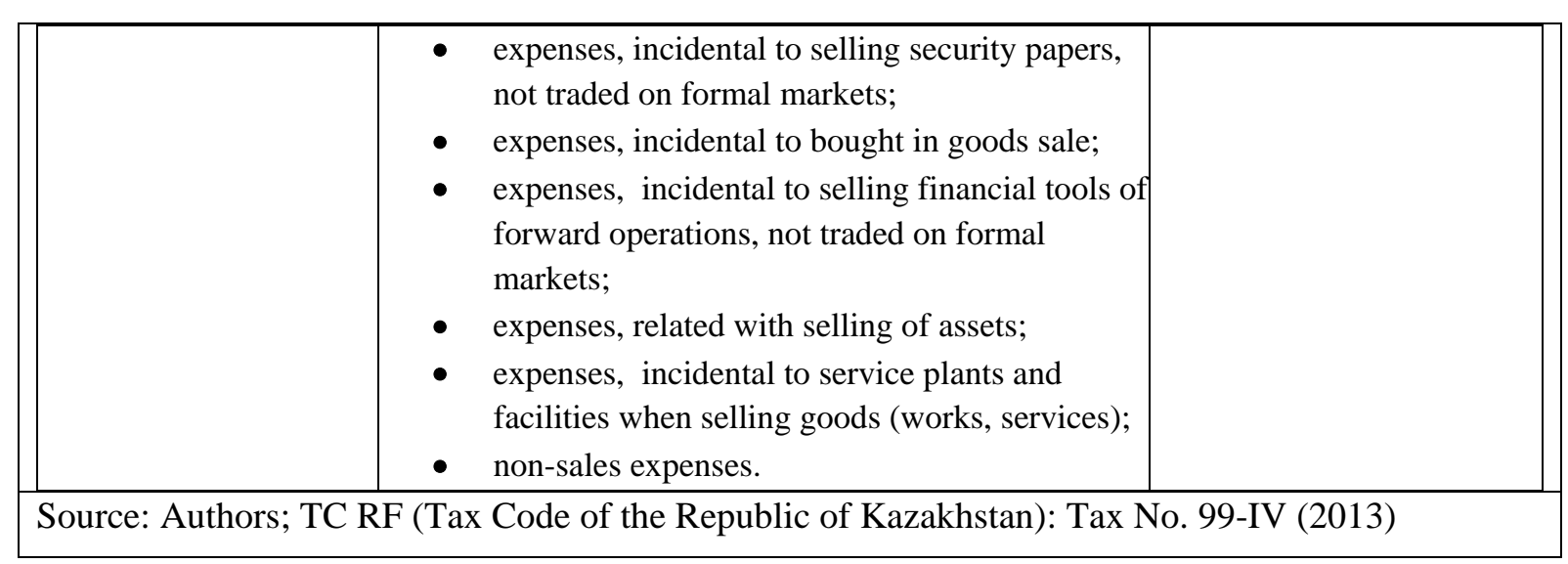

In the Tax Code of the RoK (2013), direct and indirect costs are treated uniquely. Direct expenses are strictly as stated without the economic content of costs. Indirect expenses include all other expenditure undertaken by the taxpayer during the reporting (tax) period. Therefore, there are differences in the rules of calculation of the amount of expenses that reduce income for the reporting (tax) period for tax and financial accounting.

Thus, these concepts are fundamental for both economic theory, and recording and analysis. They are of different content, and a proportion of each other.

\section{Teaching methods of cost calculation of end products}

The methods for calculating costs of production involve a set of techniques that group and allocate production costs based on "cost objects" for the different types and units of cost. These analytical methods of cost accounting determine the production facilities and calculation units.

There are different methods for accounting expenses of production and calculating production costs. The characteristics of the production process, the nature of the products (services provided), its composition, and methods of processing determine the choice of methods. The various methods are given in Figure 4.

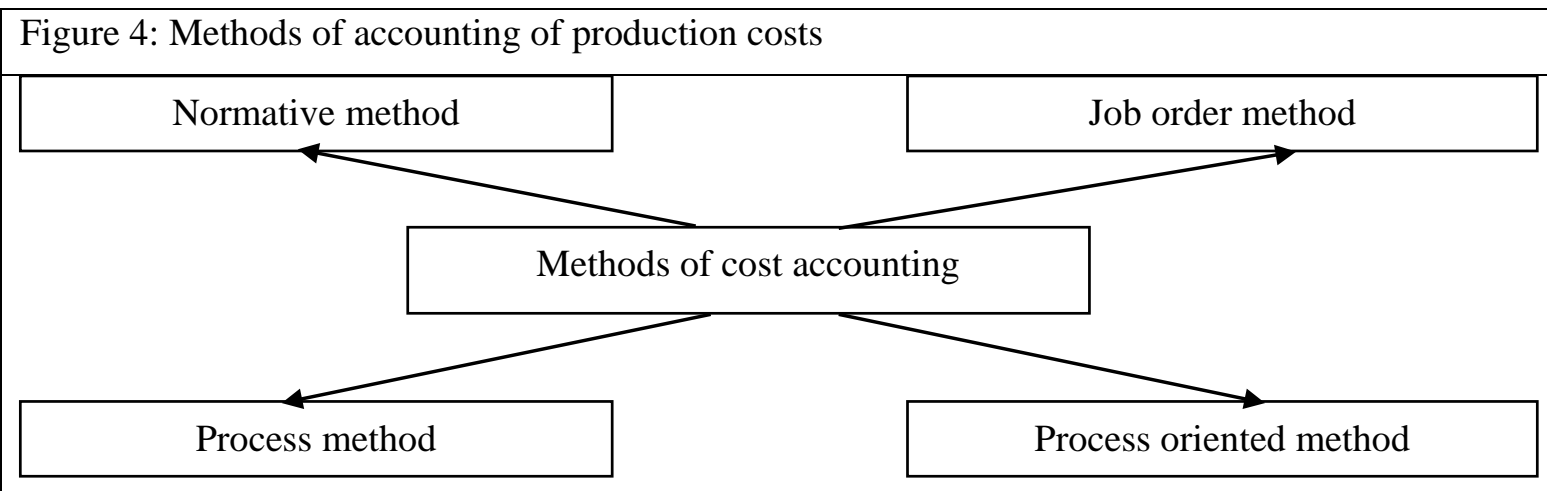

\section{Source: Authors}

The normative accounting method involves a preliminary determination of regulatory costs on operations, processes, and objects, to identify deviations from standard costs in the course of production. Adding the costs to algebraic rules and deviations determine the actual costs. In this way, an accountant deals with the regulatory costs of production and deviations.

This method aims to identify the actual production cost in terms of deviations from the norm. 
The pre-normative calculation for each type of product produced by the company characterizes the normative method, i.e. the production cost accounting begins with a calculation of the norm, regarding consumption of materials, and labor costs.

Norm is a predetermined numerical expression of economic activity in terms of advanced technology and production organizations. Normative accounting is calculated on the bases of technically justified norms of consumption of material and labor resources, which technical documentation establishes.

The normative accounting is used to determine the actual production cost, and evaluate defects and dimensions of works in progress. All changes to the existing rules are recognized during the month in the normative accounting.

All current expenses are divided into norms of consumption according to the norms and deviations identified. The normative method and production cost accounting provide the actual cost of products and allows regular analyzes of the causes of deviations to identify their causes.

The use of a normative method of cost and production cost accounting for the industrial enterprise involves a certain sequence of actions represented in the compliance figure (production cycle).

There is full and part time accounting of normative expenses. Part time accounting of normative expenses is a less accurate and less time-consuming method. Under this option, only direct costs are considered in the normative accounting, and normative calculation is made only due to them.

The job order accounting method is used in the manufacturing of unique or special order items. In the industry, it is used, as a rule, in enterprises with a single type of production organization (factories of heavy mechanical engineering, producing blooming mills, rolling mills, and large excavators).

The formation stages of production cost under the job order method of accounting are given in the Figure 5.

Distinctive features of a single type of production are:

- a wide variety of manufactured products, most of which cannot be reproduced and is produced in small quantities for individual orders;

- technological specialization of job places and inability of permanent secure of certain operations and details of the workplace;

- the use of, as a rule, of multipurpose equipment and appliances;

- a relatively large proportion of manual assembled and finishing operations;

- the prevalence among workers of a highly skilled specialists; and

- a relatively long production time.

The scope of applying the order method for accounting includes small-scale industrial enterprises. Serial means a certain number of identically constructed products, which are produced simultaneously or sequentially. Small-scale production is organized for producing goods, which customers need in small amounts.

The essence of this method is that all direct expenses are taken into account in the context of the established accounting articles on individual production orders. The rest of expenses are accounted at their places of origin and included in the production cost of individual orders in accordance with the established base (rate) of distribution.

The object of cost accounting and calculation is for a single production order, the actual production cost of which is determined after its manufacture. Thus, an order refers to the application of the client for a certain number of specially created or manufactured products. A contract with the customer determines 
the order type. It also stipulates the price paid by the customer, the order of payment, transfer of goods (works, services), and terms of the order. Until the order transfer, all expenses relating to it are considered provisional. To determine the cost of one product, the overall production expenses are divided by the number of units in a set.

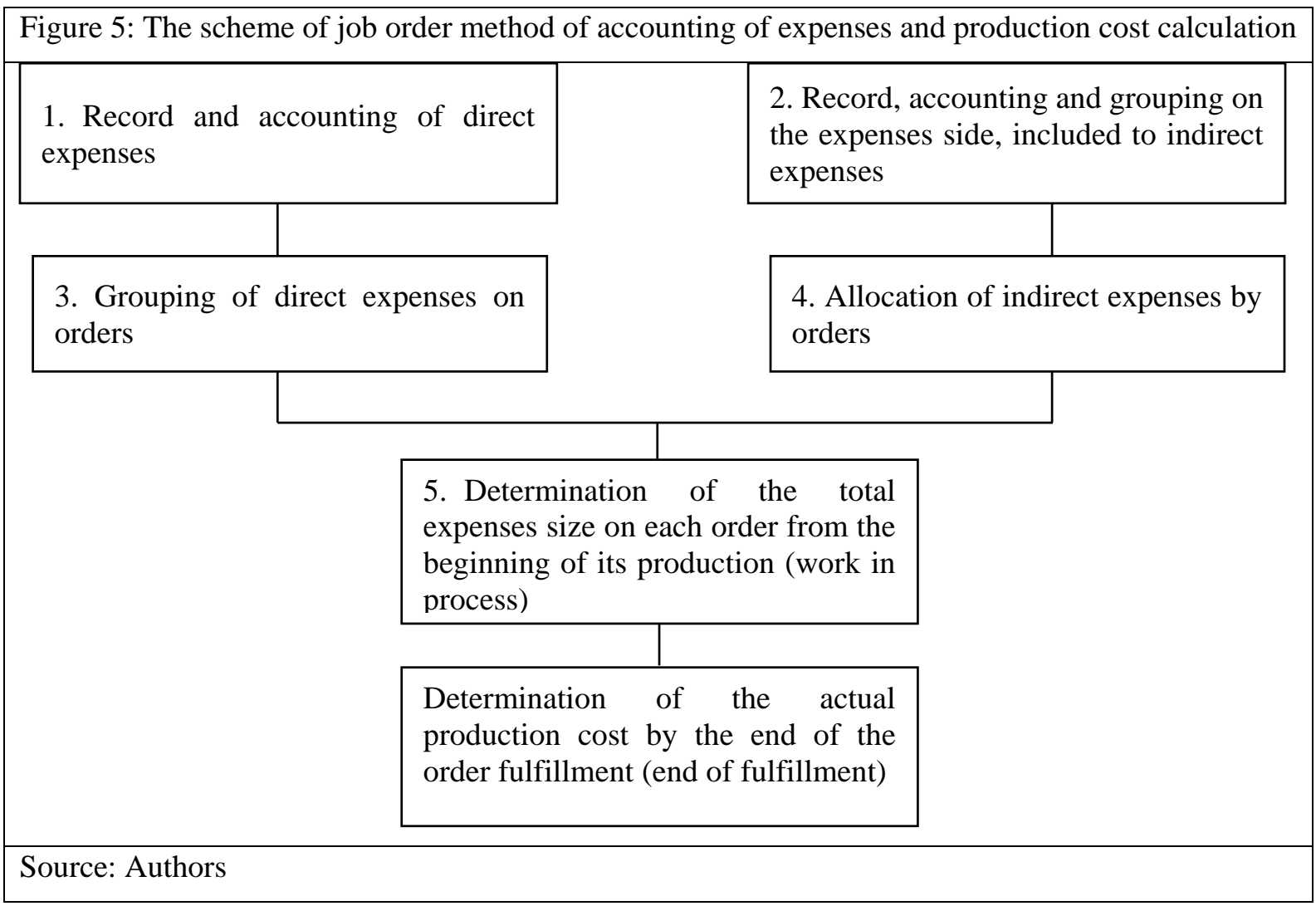

The process method of costs accounting is used in the industries with the serial and line production, when the same products are subject to a certain sequence through all stages of production. Processing is production that includes physical or chemical methods to process raw materials, and the preparation of products in several successive steps. Products of processing are objects for price calculation, including processing that produces several products at a time.

The essence of process method is that direct expenses are reflected in the current accounting not by product types, but by stages of production, even when producing several products at a times. Processing is usually the object of cost accounting.

Processing is a part of the process (a set of technical operations), ending with a semi-finished product, which is sent for further processing or sold to a third party. Hence, successive passing of raw material through all process stages results in the final product, i.e. at the output of the last processing, the products are complete, rather than semi-finished.

The process method distinguishes variants of semi-finished and finished products. The first variant is restricted in terms of accounting expenses at each process stage. The movement of semi-finished products is not reflected in the accounting records. The accounting department controls product movement in accordance with the operational records of the semi-finished products in physical terms, as recorded in the workshops. In accordance with the given procedure, the accounting of the production cost for semi-finished products is not defined after each processing, but the cost of each finished product is calculated. This direct cost accounting reflects the redistribution of each, separately. The cost of raw materials includes the cost of the product at the first processing only. The production cost of the final 
product is the sum of the costs of processing. Production costs are not calculated at the intermediate process stages.

The algorithm of determining the production cost with the process method of cost accounting and cost calculation is shown in Figure 6.

\begin{tabular}{l}
$\begin{array}{l}\text { Figure 6: The scheme of process method of accounting of production expenses and production cost } \\
\text { calculation }\end{array}$ \\
\begin{tabular}{|l|}
\hline 1. A current accounting of production expenses at costing and collective clearing of account \\
during a month
\end{tabular} \\
$\begin{array}{l}\text { 2. The closing and clearing of accounts at the end of the month by means of included costs } \\
\text { between separate types of products (works, services) on production cost accounting }\end{array}$ \\
$\begin{array}{l}\text { 3. The allocation of expenses included in production cost accounting between the finished } \\
\text { product and semi-finished product, and also between separate types of products and the } \\
\text { accounting of the production cost of a unit of product. }\end{array}$ \\
\hline \begin{tabular}{l} 
4. To compose a statement of consolidated accounting of production expenses for a month. \\
\hline Source: Authors
\end{tabular} \\
\hline
\end{tabular}

The peculiarities of the process accounting method are as follows:

1) the assimilation of costs of processing, regardless of the individual orders, to calculate the production cost of each processing;

2) the write off of costs over a calendar period, not during the manufacturing of the order;

3) simplicity and a low cost with no registration card orders, there is no need to allocate indirect costs to individual orders.

The process cost method refers to cost accounting for the process. It applies to enterprises with mass production of the same type of products, with short duration production cycle. This includes production of a limited range of products with a single unit of measurement and calculation, and the complete absence of any minor dimensions of work in progress. As a result, output quality relates to cost accounting and calculation of the object. Several stages of processing are evident in enterprises using this method.

For instance, the manufacturing of pies in a bakery involves the following processes:

- dough making;

- preparing filling;

- decorating of pies; and

- baking.

Process accounting in one form or another involves:

- production planning in general and in the context of cost flows;

- calculation of the conditional output for a certain period; 
- collection and allocation of expenses;

- the preparation of statements on production; and

- maintenance of calculation of accounts, journals, books and other accounting records that form the structure of accounting and its relationship with the system of calculation.

The scheme of the process method of expense accounting and production cost calculation is shown in the Figure 7.

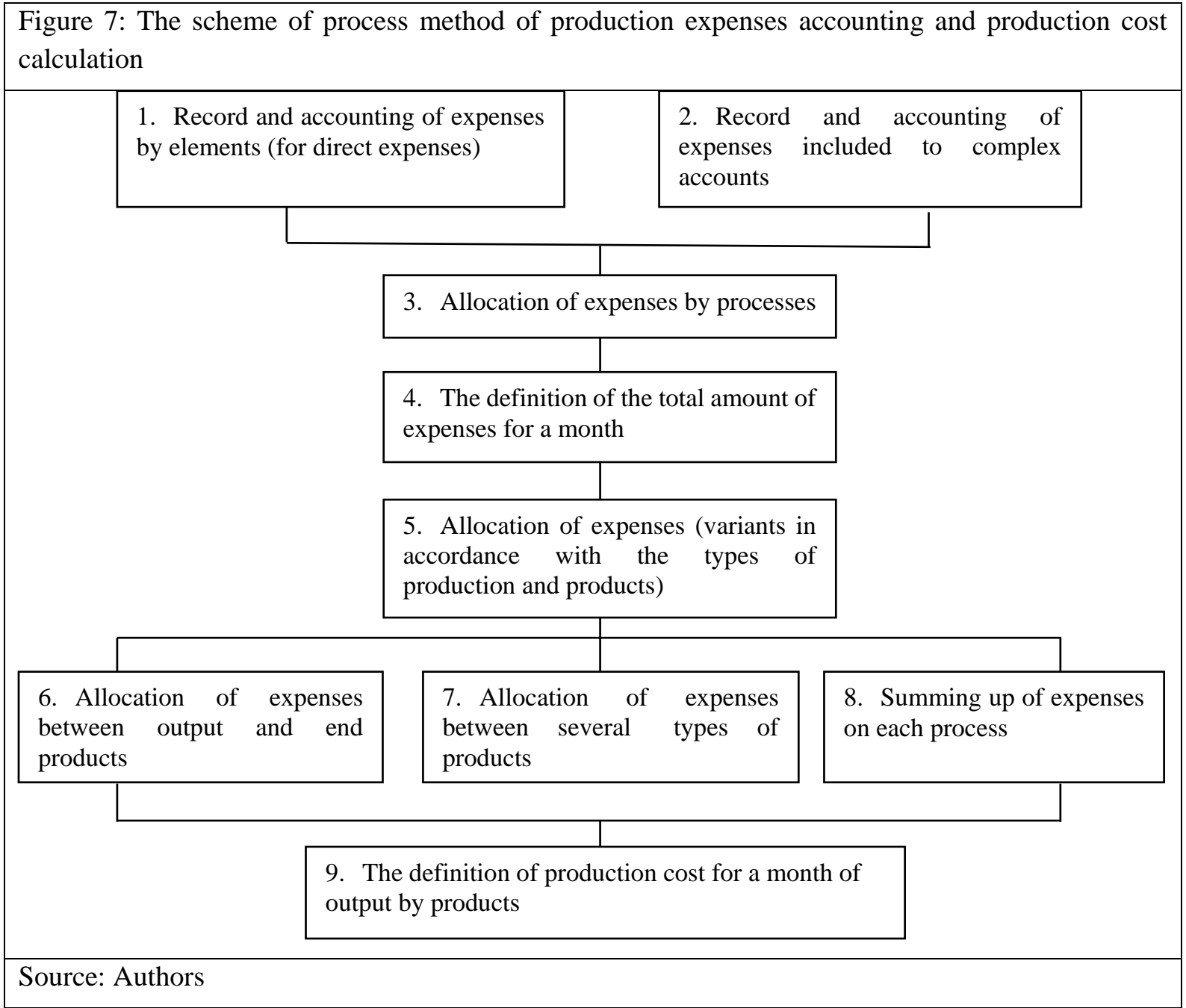

The process method of expense accounting involves the following:

1) A simple single stage accounting method, applied at industries, such as coal mining industry, where:

a) only one type of product is manufactured;

b) stocks of semi-finished products are not produced; and

c) stocks of finished products are not produced (or available in a limited quantity).

2) A simple two stage accounting method;

3) A simple multi stage accounting method, where the production process consists of several stages (processes), with an intermediate storage of semi-finished products from processing semifinished stocks. In a manufacturing organization, the abovementioned formula of accounting the production cost cannot be used, as the quantity of each semi-finished product does not coincide with the number of finished products. In this case, it is necessary to organize the 
account of costs and the number of semi-finished products manufactured for each process stage; or

4) Cost accounting on process stages to improve the analytics of accounting of the raw materials per unit of product, and to take into account separately, but as part of process, only added costs (salaries plus overhead costs) for each.

From the above characteristics of all methods of accounting the cost of finished products, we conclude that the process method is suitable for cases of producing a series of a single product. For products produced in parallel, slight changes to the model for some of the materials applies. Although the same direct labor and overhead costs are applied for every model, each will have its own direct material costs. Today, however, the actual production is much more difficult. The assortment of food industry represents numerous products produced from various materials, but with the same manufacturing processes and units. The food industry could apply a semi process method of cost accounting. For example, the process of preparing pies consists of several successive manufacturing steps, and for each, a similar technology is applied. However, the ingredients for each type of pie differ, as do the proportions. In addition, some types have different processing steps, and this exemplifies the complexity of production. Furthermore, the technique of accounting the cost of the product in such an enterprise requires methods for both process cost and order cost accounting.

In the food industry, the cost of production and its accounting proceed relatively independent of each other. However, the first process (production cost accounting) is a prerequisite for the implementation of the second process (the production cost). This is evident when considering the primary production cost accounting and allocation of direct costs on the objects of accounting (by types of product).

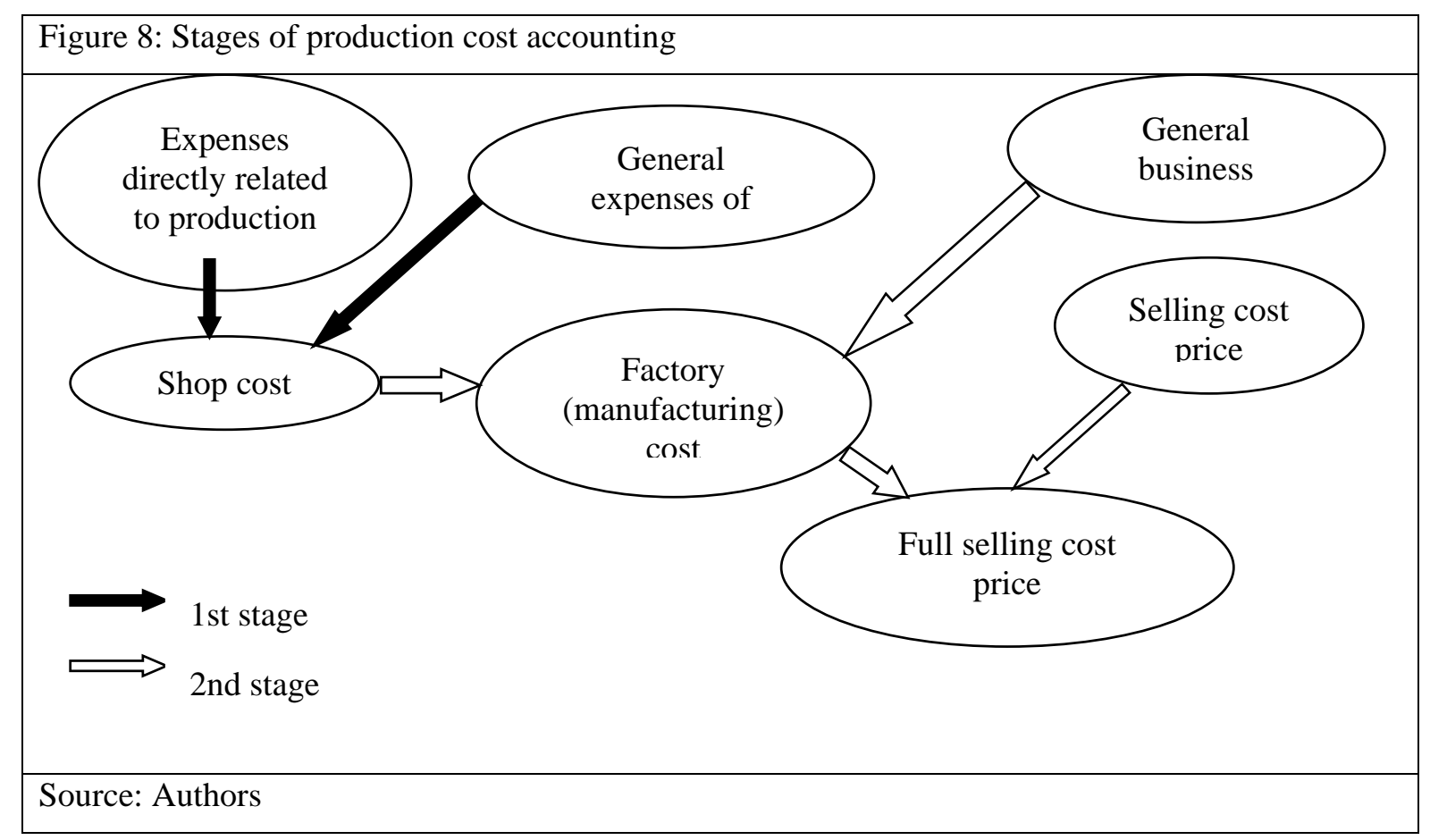

The objects of accounting organize the basis of the production cost in the food industry. Industry guidelines and recommendations play an instructive role, in choosing objects for accounting. This involves methods for evaluating the work and finished products, accounting of expenses, and the order of allocating indirect.

In the food industry, the formation of the production cost can be broken down into a series of broad steps, as shown in the Figure 8. 
The third step is the last in determining the production cost. After its entry as a debit sales under selling expenses or the period, the expense is written off. Business expenses can be direct (specific batch of sales) or indirect (total volume of sales). Direct selling expenses are debited under the appropriate batch of products. Therefore, part of these expenses under selling expenses can have cash flow in the balance. The primary objects of the accounting of production costs in the food industry are the costs of labor and materials in a variety of production operations, maintenance and operational costs, buildings and structures, and production management. Criteria group and summarize data on these primary costs, based on various accounting procedures, and this creates the necessary management accounting tool. Each object relates to certain elements of the production. Therefore, the first sign of cost grouping (or the first sign of object accounting) are the economic elements of costs.

Products can involve primary and auxiliary productions (goods released to a third party). Therefore, direct costs relate to the primary production (20) and auxiliary (23) accounts, as shown in the Figure 9.

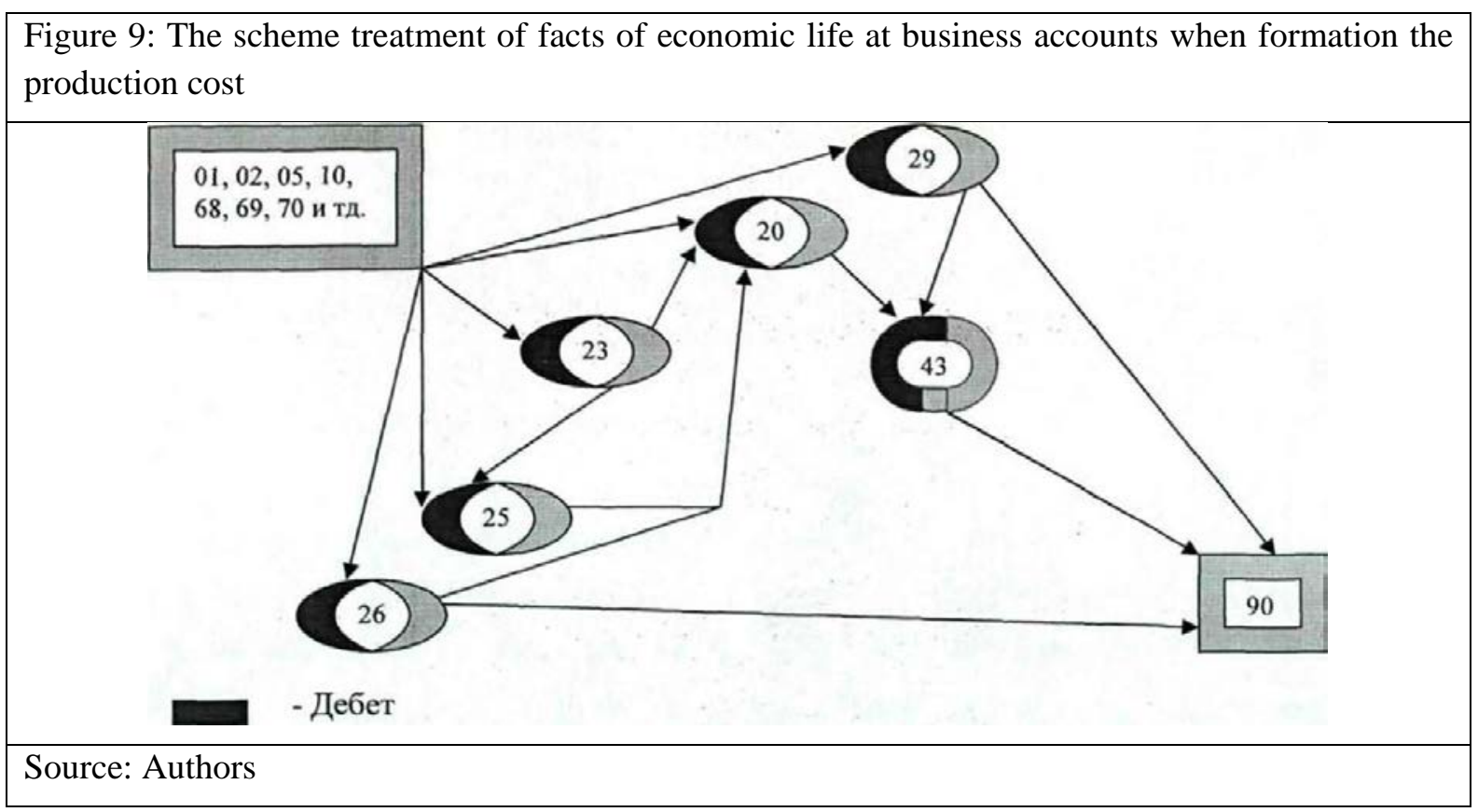

Moreover, there is no strict requirement for applying both cases. If necessary, the primary production could involve the process method and the auxiliary the order method. Since the primary and auxiliary production may belong to different sectors, then the most convenient and appropriate method of accounting should apply.

On accounting, general expenses (25) and general expenses for indirect expenses (26) are collected (Figure 9). Unlike direct, indirect expenses are untraceable to a specific type of product at the time of expense creation, such as depreciation of buildings or the costs of skills development. In this regard, these expenses are attributed to the individual products as they appear, based on primary documentation. At this stage, indirect expenses may only be included in the cost of the entire amount issued for the production period. Indirect expenses to the cost of the production volume of a particular type or in a unit cost require a special mechanism for inclusion. This occurs in the next stage. However, this does not mean that analytical accounting is not conducted at accounts for general expenses ( 25 \& 26; Figure 9). Indirect expenses, apply to costs of products only for products that cannot be made without indirect expenses. Business units traditionally conduct analyses of indirect expenses.

In the food industry, the analytical code that reflects the production cost needs to include all analytical grouping and indicators in accounting for expenses of production. The system of the primary account is an organizational and methodical form of this process. 
In contrast to the document for the organizational system of creating, testing, processing, and recording accounting documents, the primary accounting system aims to measure and reflect the production cost during production. The creation and use of primary accounting documents represent only a special case of the primary accounting.

It is necessary to create a comprehensive system of coding, regulatory reference nomenclatures, and constant and conditional information. The coding needs sufficient time for accounting. In each classification, group codes should be assigned as a key prerequisite for entry in the database of the computer. This restricts key prerequisites to the primary accounting documents.

Nevertheless, the registration and storage of primary costs, provides legal evidence of accomplishments required in accounting and appropriate control over the accuracy, appropriateness, and legality of expenses.

Grouping of expenses on economic terms shows no purpose or destination of costs incurred, the expediency in doing this, the relationships between costs, results (principle of the profit and losses) and volume of production, or other factors that directly affect the cost per unit.

It is more effective to control production costs when consuming resources of production, i.e. where the production process or a service takes place. In this regard, the analytical detailing and grouping of costs become crucial accounting objects, e.g. the place of cost occurrence. Today the development of accounting on these sites defines the main directions of improving the production accounting, control, and management of production costs.

\section{Conclusion}

The main feature of the food industry is their branching of primary and auxiliary production facilities, service industries, and farms. In addition, in recent times there is a shift in the food industry to multipurpose facilities, where production and trading occur simultaneously.

Overall, accounting plays a significant role in organizing a business entity. It affects the composition of production costs, the structure of the working plan of accounts, the organization of relevant analytical accounting, and other areas of commerce. As well, the structure of industrial organization affects the type of accounting service, the degree of production, and the volume of accounting operations.

It is therefore necessary to not only keep records, but also analyze and monitor the techniques, which depend on the characteristics of the enterprise and industry specified.

\section{References}

Anthony, R., \& Rice, G. (2001). A stereotype (2nd ed.). Moscow: Finance and Statistics (Series on Accounting and Auditing). Bezrukih, P. S., Ivashkevich, V. B., \& Kondrakov, N. P. (1996). Accounting: Study guide (2nd ed.). Moscow: Accounting. Brusentsova, V. I. (2002). Regulatory cost accounting in continuous production.

Horngren, C. T., \& Foster, J. (1995). Accounting: managerial aspects (Trans.). Moscow: Finance and statistics.

Ivashkevich, V. B. (2003). Managerial accounting. Study guide. Moscow: Economist.

Khamidullina, G. R. (2004). Cost management: planning, accounting, control and analysis of distribution costs. Moscow: Examination.

Komissarova, I. P. (2002). Transformation of expenses accounting of the organization: methodology and practice. Mosccow: Accounting.

Kondrakov, N. P., \& Ivanova, M.A. (2003). Managerial accounting: Study guide. Moscow: INFRAM.

Kondrakov, N. P. (2008). Accounting: Study guide (5th ed.) Moscow: INFRAM.

Kotliarov, S. A. (2002) Cost Management.

Kukukina, I. G. (2011). Methodologies and tools management of financial flows in the transformation Corporate Control.

Nikolayeva, S. A. (2000). Profit and costs of the enterprise: practice, theory, perspectives. Moscow: AnalitikaPress.

Nikolaeva, O. E., \& Shishkova, T. V. (2009). International Financial Reporting Standards. 
Popova, L. V., Golovina, T. A., \& Maslova, I. A. (2006). Modern managerial accounting. Theory and practice of controlling: study guide. Moscow: Business and service.

Popova, L. V. (2001). Managerial analysis of the formation of the optimal price of industrial production Accounting system and financial control reformation when transition to international standards: Scientific practical conference materials. Orel: Orel HTU.

Popova, L. V. (2007). Cost accounting, calculation and budgeting at individual industries: courseware. Moscow: Business and service.

Rudenko, V. I. (2005). 50 M Management: A Handbook for exam preparation (4th ed.). Phoenix: Rostov (Tests and exams). Sokolov, A. V. (Ed.). (2004). Finance and Statistics. Managerial Accounting Overhead.

Tax Code of the Republic of Kazakhstan. (2013). Retrieved from http://www.salyk.gov.kz/eng/nk/documents/ taxcode022013.pdf 